\title{
Comparison of northern hemispheric anthropogenic black carbon emissions from global datasets
}

\author{
$\underline{\text { V.-V.Paunu }}^{\text {a }}$ and K. Kupiainen ${ }^{\mathrm{a}}$ \\ ${ }^{a}$ Finnish Environment Institute SYKE \\ Email: ville-veikko.paunu@ymparisto.fi
}

\begin{abstract}
There is a large interest in the impact of short-lived climate pollutants (SLCPs) for the Arctic climate but the performance of emission inventories that serve as input to climate models remains unknown especially in high latitudes. To assess emissions that are expected to have a more direct impact on the Arctic, a comparison of available SLCP emission inventories was conducted utilizing spatially-distributed global emission datasets downloaded from the ECCAD-GEIA website (http://eccad.sedoo.fr). In this paper, the comparison was done for black carbon emissions. Differences in both emissions and their locations were addressed.

There remains large variation between the emission inventories in northern latitudes. Relatively speaking the variability is larger than at the global level. Total emissions at high latitudes tend to be lower which makes them more sensitive to uncertainties in regionally important source sectors than at the global level. Variations within the sector emission estimates arise most likely from uncertainties in key parameters, i.e. activities and emission factors. The accuracy of the parameters needs further development. However, the differences were unsystematic, so this was not enough to explain the variation. Some of the variation is due to differences in inclusion of relevant source sectors and spatial distributions of the emission data. Notably flaring was included to the full extent only in some inventories, although the emissions are significant in the Arctic region. Another sector omitted in some inventories was international maritime transport. Inclusion of relevant emission sectors is a common improvement suggestion for all models.
\end{abstract}

Another aspect affecting the quality of emission inventories is the location of the emissions. The spatial aspect is especially important in the case of black carbon, since its life-time is relatively short and, therefore, the concentration around the sources is higher. This is highlighted in the Arctic area in particular, since black carbon reduces albedo and thus enhances melting when deposited on snow or ice.

There were significant differences between the spatial distributions of the black carbon emissions in the inventories, often with no spatial agreement at all. The differences also varied between source sectors, being sometimes mostly systematic, unsystematic or both. Uncertainty in the spatial distribution of the emissions potentially increases the uncertainty of impact modelling. The differences indicated that the inventories use different spatial proxies for the emissions. One way to develop the quality of the spatial distribution would be to incorporate more data from national or regional emission inventories or models into the global inventories, provided their quality is sufficient.

Keywords: Short-lived climate pollutants, black carbon, Arctic, emission modelling, spatial agreement 


\section{INTRODUCTION}

The Arctic climate is warming faster than the global average (Quinn et al., 2008). Furthermore, Arctic sea ice cover has been decreasing as well. Alongside with carbon dioxide, the main contributors to climate change are so called short-lived climate pollutants (SLCPs), such as black carbon (BC) (Quinn et al., 2008; Koch et al., 2011; AMAP 2015).

To assess the impact of SLCPs on the Arctic climate, climate modelling is needed. All climate models rely on global emission inventories for input data. The emission inventories have differences in emission amounts and their spatial distributions. The performance of the inventories especially in the Arctic region remains uncertain. While global SLCP emissions have an impact on the Arctic, pollutants emitted closer to the Arctic typically have higher impact per emitted mass. This highlights the importance of reliable spatial and temporal estimations of emission sources. For example, Stohl et al. (2013) demonstrated that the inclusion of flaring emissions in high northern latitudes together with daily varying emissions form residential combustion resulted in a better match between modelled and observed concentrations of black carbon in the Arctic.

One of the most important SLCPs in the Arctic is black carbon (BC). It is a solid particle formed in incomplete combustion (Bond et al., 2013). It absorbs visible light efficiently, and thus warms the atmosphere. $\mathrm{BC}$ is especially important in the Arctic. It decreases the albedo of snow and ice on deposition, thus enhancing melting. According to the definition by Bond et al. (2013), BC is also refractory, insoluble to water and common organic solvents, and formed in flames, making it distinguishable from carbonaceous compounds in the atmosphere. The lifetime of $\mathrm{BC}$ is about a week, main removal process being wet or dry deposition to the surface. Therefore, emission reductions of $\mathrm{BC}$ have a relatively quick effect on its atmospheric concentration.

Black carbon is a form of particulate matter (PM), which has well established adverse health effects with no safe exposure level (WHO, 2013). BC seems to be a better indicator than undifferentiated PM mass of harmful PM species from combustion. Reductions of $\mathrm{BC}$ emissions should, therefore, also reduce health effects from PM (WHO, 2012).

To get an estimate of the quality of the inventories, the research questions of this study were: (1) what kind of differences are there in global emission inventories in the Arctic; and (2) how can the models be improved?

\section{METHODS}

\subsection{Global Emission Inventories}

The global BC emission inventories that were compared were downloaded from the ECCAD-GEIA website (http://eccad.sedoo.fr). The products were ECLIPSE GAINS version 4 (Klimont et al., 2015 in preparation), ACCMIP (Lamarque et al., 2010), and PEGASOS (Braspenning Radu, in preparation). Newer version of ECLIPSE, version 5 (Klimont et al., 2015 in preparation; Stohl et al., 2015) which is based on the previous version, was also included in the comparison. The models were compared at the global scale, in northern latitudes and regionally. Furthermore, the spatial distributions of the emissions were compared. Both sectoral and total emissions were studied.

The inventories didn't share a common year. The years used were 2000 for ACCMIP and PEGASOS and 2005 for ECLIPSE GAINS 4 and 5. The scenarios used with the inventories were: current legislation (CLE) for ECLIPSE GAINS version 4 and 5; and PBL 2005FRZ (developed by Netherlands Environmental Impact Assessment Agency) for PEGASOS. The unit for the emissions from the ECCAD-GEIA website was $\mathrm{kg} \mathrm{m}^{-2}$ $\mathrm{s}^{-1}$, which was converted to kiloton per year.

All inventories included following emission sectors: land transportation, energy production and distribution, waste treatment and disposal, industrial processes and combustion, residential and commercial combustion, agricultural waste burning and agricultural production. ACCMIP also included aviation and maritime transport sectors.

The $\mathrm{BC}$ emission of latitudes north of $60^{\circ}$ were separated from the inventories and compared as totals and sector-by-sector. This was also done for five regions: USA, Canada, Russia, Nordic countries and other Europe. The spatial distributions of the emissions were inspected on a map to compare certain hot spots and to identify clear sectoral differences between the inventories. 


\subsection{Agreement Coefficient}

To assess the spatial agreement of different inventories, agreement coefficient (AC) developed by Ji and Gallo (2006) was used. AC is symmetric, bounded and non-dimensional measure of agreement. Full definition can be found in Ji and Gallo (2006), but in short

$$
A C=1-\frac{S E D}{S P O D}
$$

where SSD is the sum of square difference

$$
S S D=\sum_{i=1}^{n}\left(X_{t}-Y_{i}\right)^{2},
$$

and SPOD is the sum of potential difference

$$
S P O D=\sum_{i=1}^{n}\left(|\bar{X}-\bar{Y}|+\left|X_{i}-\bar{X}\right|\right)\left(|\bar{X}-\bar{Y}|+\left|Y_{i}-\bar{Y}\right|\right),
$$

where $\bar{X}$ and $\bar{Y}$ are the means of datasets $X$ and $Y$. When $A C=1, X$ and $Y$ have perfect agreement, and values less than or equal to zero indicate no agreement. Systematic and unsystematic agreements can be calculated separately. The unsystematic sum of product-difference is defined as

$$
S P D_{w}=\sum_{i=1}^{n}\left(\left|X_{t}-P\right|\right)\left(\left|Y_{t}-P\right|\right)
$$

where $\hat{X}$ and $\hat{\gamma}$ are gotten from geometric mean functional relationship (GMFR) model. Systematic sum of product difference can be calculated as

$$
S P D_{s}=S S D-S P D_{\mathrm{w}} \text {. }
$$

Finally, systematic and unsystematic agreement coefficients can be calculated by

$$
A C_{g}=1-\frac{S P Q_{s}}{S P O D}
$$

and

$$
A C_{\mathrm{w}}=1-\frac{S D Q_{\mathrm{w}}}{S P O D}
$$

In practice, systematic difference is the difference that could be corrected from the other dataset by a linear model. Unsystematic difference represents random differences unrelated to the other dataset. AC was calculated between all datasets for $\mathrm{BC}$ emissions north of $60^{\circ}$ latitude, for both total and sectoral emissions.

\section{RESULTS}

\subsection{Emissions North of $60^{\circ}$ Latitude}

Total BC emissions in the inventories differ somewhat. Lowest global emissions are in ACCMIP, which are $75 \%$ of the highest emissions, from ECLIPSEv5 (5150 and $6860 \mathrm{kt} / \mathrm{year}$, respectively). In the Arctic the differences are larger. Figure 1 shows the total and sectoral $\mathrm{BC}$ emissions for the inventories north of $60^{\circ}$ latitude. Lowest emissions north of $60^{\circ}$ latitude are in ACCMIP, which are only $27 \%$ of the emissions from ECLIPSEv4 (25.8 and $94.1 \mathrm{kt} / \mathrm{year}$, respectively), which has the highest emissions. This is mostly explained by the better inclusion of flaring emissions in oil and gas extraction within the energy production and distribution sector. North of $60^{\circ}$ latitude this mainly consists of activity in Timan-Pechora and YamaloNenets areas in Russia. Emissions north of $60^{\circ}$ latitude comprise between $0.5 \%$ (ACCMIP) and $1.7 \%$ (ECLIPSEv4) of global BC emissions.

Sectors with the highest $\mathrm{BC}$ emissions north of $60^{\circ}$ latitude vary between the inventories. For ECLIPSEv4 and 5 the sector with highest emissions is energy production and distribution, which comprises $83 \%$ of the total BC emissions. Next comes land transport and residential and commercial combustion, with $8 \%$ each. In PEGASOS land transport has the highest emissions, with residential and commercial combustion and industrial sectors close behind. For ACCMIP the highest sectors are the same, only residential and commercial combustion having highest emissions and land transport second highest. In all inventories the three most important emissions sectors make up $90.3-98.5 \%$ of the total BC emissions. Only ACCMIP included maritime transport emissions, and it comprises $5.3 \%$ of the total emissions.

The biggest differences between the inventories are in the energy production and distribution and industrial sectors. Both ECLIPSE versions have significantly higher emissions (about 300 times higher) than other 
inventories in the energy sector. ECLIPSE includes higher flaring emissions, which explains most of the difference. On the other hand, the ECLIPSE inventories have smaller industrial emissions than other inventories (up to eight times lower emissions). It seems that the others include some flaring in the industrial sector, but not to the same extent as ECLIPSE in the energy sector. Differences in the two other important emission sectors, land transport and residential and commercial combustion, are smaller between all inventories. Emissions between the highest and lowest estimate were 1.7- and 1.5-fold, respectively (between PEGASOS and ECLIPSEv5 in both cases).

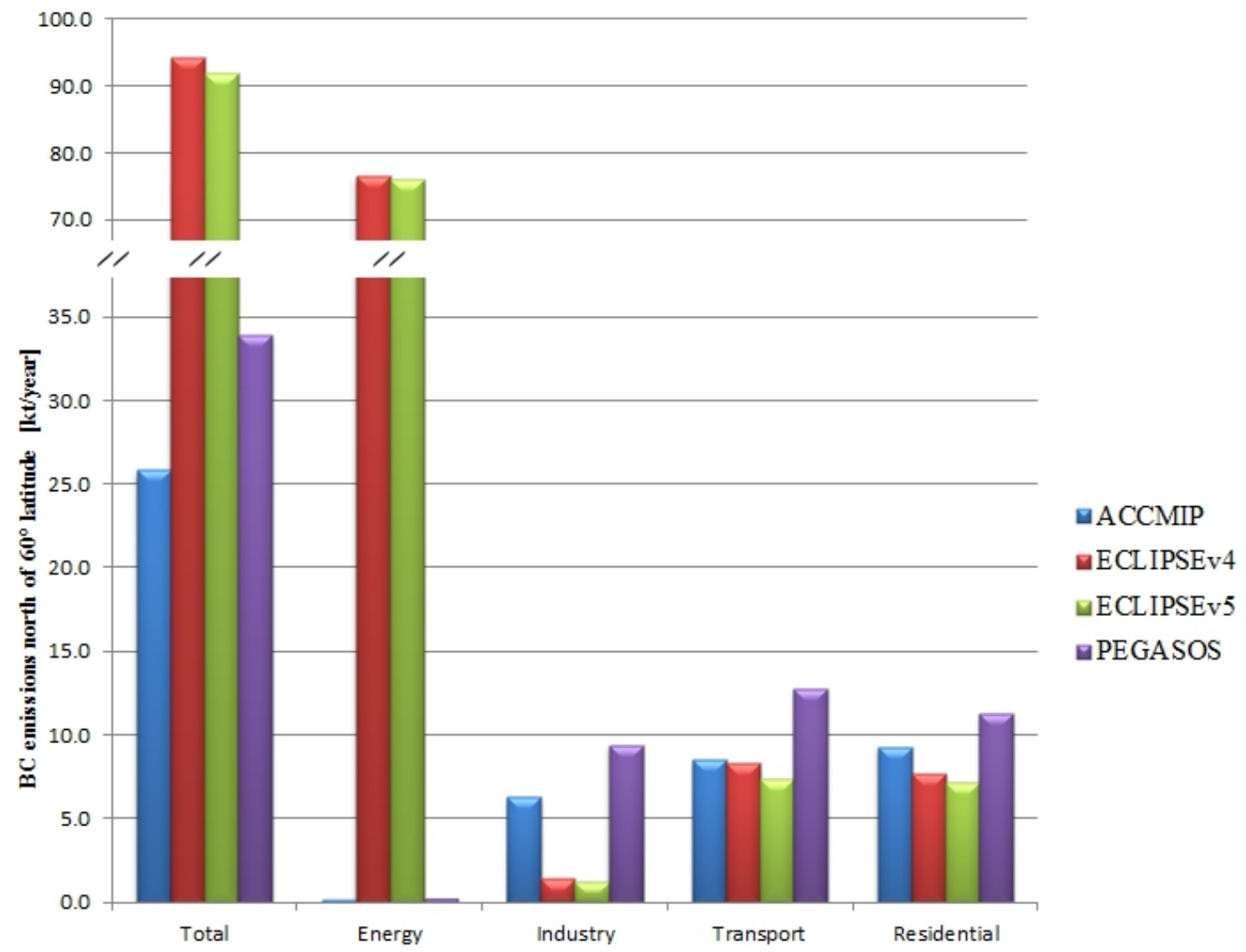

Figure 1. Black carbon emissions north of $60^{\circ}$ latitude. Emissions presented as total and per four most important sectors.

Regional emissions are presented in figure 2. The region other Europe has the highest emissions in all inventories, with USA second and Russia third. Differences between the inventories are noticeable in all regions. The differences are also not systematic, although PEGASOS has the highest emissions in all regions but Russia. The largest differences in sectoral emissions are in the energy sector in Russia, mainly because of the flaring emissions which are included in both ECLIPSE versions but seem to be omitted in other inventories. In contrast, ECLIPSE has much lower industrial emissions in all regions. In the third most important emission sector, residential and commercial combustion, ECLIPSE has significantly lower emissions in Russia, but highest in other regions except USA. In general the sectoral emission differences are as with the total emissions, unsystematic within the regions and between the inventories. 


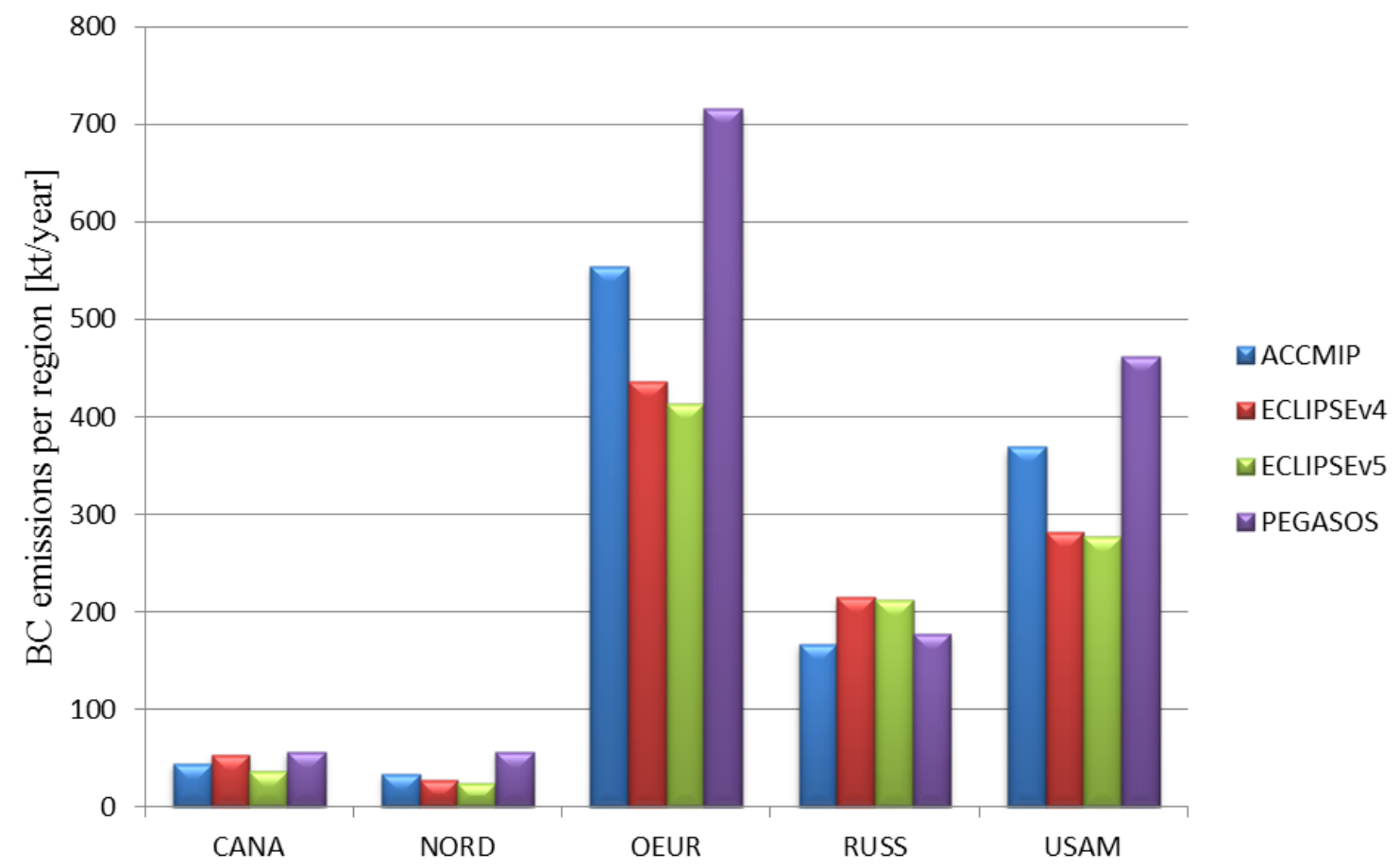

Figure 2. Black carbon emissions per region.

\subsection{Spatial Distribution of the Emissions}

In general, PEGASOS and ACCMIP have similar spatial distributions for BC emissions. ECLIPSEv4 and 5 have bigger differences between them and the other datasets. PEGASOS has much higher values in cells with high population density. None of the models include Greenland's emissions. Sector-wise, the biggest differences are in two sectors. In energy production and distribution flaring seemed to be only included in the ECLIPSE inventories. In residential and commercial combustion the ECLIPSE inventories has clearly different spatial proxies compared to the other inventories, especially in the Nordic countries and Canada.

The agreement coefficients for emission distribution north of $60^{\circ}$ latitude are presented in table 1 . ECLIPSEv4 and 5 have, naturally, a high AC value of 0.998. ACCMIP and PEGASOS have an AC of 0.558. The ACs and $\mathrm{ACu}$ are 0.800 and 0.758 , respectively, indicating that there was some similarity between the models, but systematic and unsystematic differences together brought the total AC down. The same can be seen between PEGASOS and ACCMIP. Between ECLIPSE versions and other models AC values are small, indicating poor spatial resemblance between the models.

Sectoral differences in the spatial distribution of the emissions vary markedly. ACCMIP and ECLIPSEv4 have a high value in land transportation sector, in which unsystematic difference made most of the disparity. In the energy and industrial sectors between these models, unsystematic difference was small, but systematic difference large enough to indicate no systematic similarity between the inventories. For the residential and commercial combustion sector the situation was the opposite, with unsystematic differences showing no similarity and systematic differences being small. Results between ECLIPSEv4 and PEGASOS are similar, except the land transportation sector has a small agreement coefficient. Between ACCMIP and PEGASOS the differences were smaller, but only the residential and commercial combustion sector showing pretty good agreement, with energy having relatively higher total agreement as well. ECLIPSE versions have nearly identical results when they are compared to other models.

The agreement coefficients show that there is large variation in the spatial distribution of the emissions between the inventories. Depending on the sector, the differences are systematic, unsystematic or both. Systematic difference might indicate that the emissions are higher in general in one model. Unsystematic difference might indicate different spatial proxies for the emissions. The largest unsystematic differences are in residential and commercial combustion sectors between ECLIPSE and other inventories. In some cases, high systematic differences are at least partly explained by the large number of zero values in one inventory in cells where the other inventory had emissions. 
Table 1. Agreement coefficients between the inventories for $\mathrm{BC}$ emissions north of $60^{\circ}$ latitude. Values below or less than 0.1 above zero, indicating no spatial agreement are marked in red. Values higher than 0.8 are marked, indicating high spatial agreement, are marked in green. AC is the agreement coefficient, and ACs and $\mathrm{ACu}$ are systematic and unsystematic $\mathrm{AC}$, respectively.

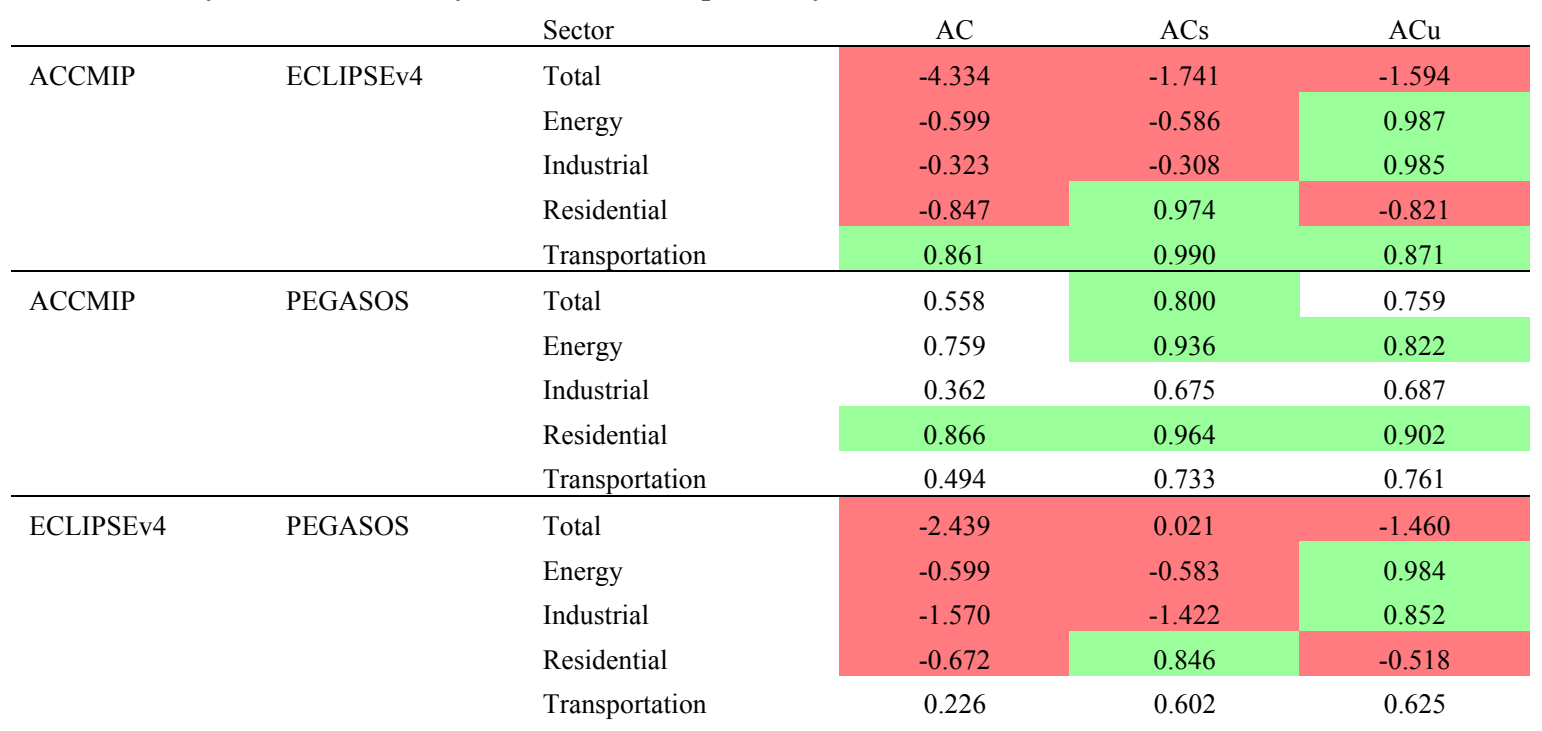

\section{DISCUSSION AND CONCLUSIONS}

This study compared the black carbon (BC) emissions of global short-lived climate pollutant (SLCP) inventories in and close to the Arctic. The results show that there are significant differences both in sectoral and regional emissions in the different inventories, and the differences are larger in the Arctic than at the global scale. Differences within sectors were most likely because of different activity and emission factor data within the inventories. But the unsystematic nature of the differences indicated that this alone wasn't enough to explain the variation.

Only ECLIPSE seemed to include flaring in the energy sector at a large scale. Other inventories seemed to have some flaring in the industrial sector, but not to the same extent. The flaring emission estimates in ECLIPSE show the magnitude of the sector may have, and underlines the importance of the incorporation of the emissions into other inventories. International maritime transport was only included in ACCMIP inventory. While the emissions from shipping still comprise only a small portion of the total emissions, the Arctic shipping has been predicted to increase in the future as the Arctic ice extent shrinks. These emissions would also occur within the Arctic area, possibly enhancing their effect.

Regional BC emissions varied greatly especially within specific source sectors. The variation between the inventories and within regions was also unsystematic. This indicates that as different sectors need more attention, also the quality of regional emissions should be increased. One way to achieve this is to incorporate more data from national or regional emission inventories or models into the global inventories, provided their quality is sufficient. None of the emissions included emissions from Greenland. The emissions from Greenland are likely to be small, but would provide more comprehensive geographical coverage.

Black carbon accounts for $20-25 \%$ of the Arctic temperature change in this century (Quinn et al. 2008), and Arctic Council countries account for 30\% (AMAP 2015). This study shows that the differences in the BC emissions between the inventories are globally $25 \%$ and north of $60^{\circ} 70 \%$. Combining these numbers indicate that the uncertainty effect on climate modelling might be notable. However, to quantify the effects to the modelling, sensitivity studies with the models are needed.

Seasonal variability of the emissions was not included in this study as they were not available in the ECCAD website for most models and sectors. It should be noted, however, that variation between seasons has a significant effect on the impacts of the emissions. For example, black carbon has a higher impact in the winter timer, when snow and ice covers are larger. Another notable aspect is that black carbon is released with co-emitted species. These pollutants, such as sulphur dioxide and organic carbon, also affect the climate and health. In comprehensive impact studies these pollutants need to be taken into account together with black carbon in order to get the overall effect of the emissions. 
In future work we will include regional inventories in the comparison. We will take a closer look at the spatial proxies used in the inventories. Also the emissions from other SLCPs will be incorporated to the comparison. Known emission hot spots will be looked into more closely. As well as emissions and their spatial distribution, the activity and emissions factor values behind the calculations would help to build the complete picture of the differences between the inventories.

\section{ACKNOWLEDGMENTS}

This work was supported by WHITE project funded by Academy of Finland, ADHIW project funded by NordForsk, and International Institute for Applied Systems Analysis (IIASA).

\section{REFERENCES}

AMAP, (2015). Summary for Policy Makers. Arctic Climate Issues 2015 Short-Lived Climate Pollutants. 15 pp.

Bond, T.C., Doherty, S.J., Fahey, D.W., Forster, P.M., Berntsen, T., Deangelo, B.J., Flanner, M.G., Ghan, S., Kärcher, B., Koch, D., Kinne, S., Kondo, Y., Quinn, P.K., Sarofim, M.C., Schultz, M.G., Schulz, M., Venkataraman, C., Zhang, H., Zhang, S., Bellouin, N., Guttikunda, S.K., Hopke, P.K., Jacobson, M.Z., Kaiser, J.W., Klimont, Z., Lohmann, U., Schwarz, J.P., Shindell, D., Storelvmo, T., Warren, S.G. \& Zender, C.S. (2013). Bounding the role of black carbon in the climate system: A scientific assessment. Journal of Geophysical Research D: Atmospheres, 118(11), 5380-5552.

Ji, L., \& Gallo, K. (2006). An agreement coefficient for image comparison. Photogrammetric Engineering and Remote Sensing, 72(7), 823-833.

Klimont Z., K. Kupiainen, C. Heyes, P. Purohit, J. Cofala, P. Rafaj, J. Borken-Kleefeld, W. Schöpp, (2015) Global anthropogenic emissions of particulate matter (in preparation)

Koch, D., S. E. Bauer, A. Del Genio, G. Faluvegi, J. R. McConnell, S. Menon, R. L. Miller, D. Rind, R. Ruedy, G. A. Schmidt, and D. Shindell (2011). Coupled aerosol-chemistry-climate twentieth-century transient model investigation: Trends in short-lived species and climate responses. Journal of Climate 24, 2693-2714, doi: 10.1175/2011JCLI3582.1.

Lamarque, J-F., T. C. Bond, V. Eyring, C. Granier, A. Heil, Z. Klimont, D. Lee, C. Liousse, A. Mieville, B. Owen, M. G. Schultz, D. Shindell, S. J. Smith, E. Stehfest, J. Van Aardenne, O. R. Cooper, M. Kainuma, N. Mahowald, J. R. McConnell, V. Naik, K. Riahi, and D. P. van Vuuren, (2010), Historical (1850-2000) gridded anthropogenic and biomass burning emissions of reactive gases and aerosols: methodology and application, Atmospheric Chemistry and Physics 10: 7017-7039

Quinn, P.K., T.S. Bates, E. Baum, N. Doubleday, A.M. Fiore, M. Flanner, A. Fridlind, T.J. Garrett, D. Koch, S. Menon, D. Shindell, A. Stohl and S.G. Warren, (2008). Short-lived pollutants in the Arctic: their climate impact and possible mitigation strategies. Atmospheric Chemistry and Physics 8, 1723-1735.

Braspenning Radu O., van Vuuren D. P., Klimont Z., Deetman S., Maenhout G., Muntean M., (2013), Interactions between climate change and air pollution scenarios and the impact of climate policy on several air pollutants assumptions (in preparation)

A. Stohl, Z. Klimont, S. Eckhardt, K. Kupiainen, V. P. Shevchenko, V. M. Kopeikin, and A. N. Novigatsky (2013). Black carbon in the Arctic: the underestimated role of gas flaring and residential combustion emissions. Atmos. Chem. Phys. 13, 8833-8855.

Stohl A., Aamaas B., Amann M., Baker L. H., Bellouin N., Berntsen T. K., Boucher O., Cherian R., Collins W., Daskalakis N., Dusinska M., Eckhardt S., Fuglestvedt J. S., Harju M., Heyes C., Hodnebrog Ø., Hao J., Im U., Kanakidou M., Klimont Z., Kupiainen K., Law K. S., Lund M. T., Maas R., MacIntosh C. R., Myhre G., Myriokefalitakis S., Olivié D., Quaas J., Quennehen B., Raut J.-C., Rumbold S. T., Samset B. H., Schulz M., Seland Ø., Shine K. P., Skeie R. B., Wang S., Yttri K. E., and Zhu T. (2015). Evaluating the climate and air quality impacts of short-lived pollutants. Atmos. Chem. Phys. Discuss., 15, 15155 15241 .

WHO, (2012). Health Effects of Black Carbon. The WHO European Centre for Environment and Health, Bonn, WHO Regional Office for Europe. $86 \mathrm{pp}$.

WHO, (2013). Review of evidence on health aspects of air pollution - REVIHAAP Project. Technical report. The WHO European Centre for Environment and Health, Bonn, WHO Regional Office for Europe. 302 pp. 